J Venom Anim Toxins incl Trop Dis, 2019 25: e144418

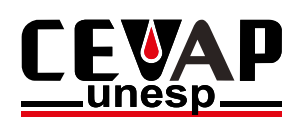

The Journal of Venomous Animals and

Toxins including Tropical Diseases

ISSN 1678-9199

Journal homepage www.jvat.org

\title{
Nitro-Heterocyclic compounds induce apoptosis-like effects in Leishmania (L). amazonensis promastigotes
}

\author{
Daiane Barros Dias Mendonça ${ }^{1,2}$, Renata Ellen Costa Silva ${ }^{1,2}$, Fanny Palace-Berl ${ }^{3}$, Cleusa FH Takakura ${ }^{4}$, Sandra \\ Regina C Soares ${ }^{5}$, Lucia Maria Almeida Braz ${ }^{1,2}$, Leoberto Costa Tavares ${ }^{3}$, Jose Angelo Lauletta Lindoso ${ }^{1,2,6,7, *}$ (D) \\ ${ }^{1}$ Laboratory of Serum Epidemiology, Faculty of Medicine, University of São Paulo, São Paulo, SP, Brazil. \\ ${ }^{2}$ Institute of Tropical Medicine, University of São Paulo, São Paulo, SP, Brazil. \\ ${ }^{3}$ Laboratory of Planning and Development of Pharmaceuticals, Department of Biochemical-Pharmaceutical Technology, Faculty of Pharmacy, \\ University of São Paulo, São Paulo, SP, Brazil. \\ ${ }^{4}$ Department of Pathology, Faculty of Medicine, University of São Paulo, São Paulo, SP, Brazil. \\ ${ }^{5}$ Laboratory of Protozoology, Institute of Tropical Medicine, Faculty of Medicine, University of São Paulo, São Paulo, SP, Brazil. \\ ${ }^{6}$ Institute of Infectology Emilio Ribas, Secretary of State for Health, São Paulo, SP, Brazil. \\ ${ }^{7}$ Center for Tropical Medicine, Faculty of Medicine, University of Brasilia, Brasilia, Federal District, Brazil.
}

\section{Article Info Keywords:}

Leishmaniasis treatment

Nitro-heterocyclic

compounds

Leishmania (L.) amazonensis

\begin{abstract}
Background: Three drugs - pentavalent antimonials, amphotericin B and pentamidine - are currently used for leishmaniasis treatment. They are administered for long periods, only parenterally, and have high cardiac, renal and hepatic toxicities. Therefore, the investigation of new compounds is required. Nitro-heterocyclic derivatives have been used as possible drug candidates to treat diseases caused by trypanosomatids.

Methods: Leishmania (L.) amazonensis promastigotes (MHO/BR/73/M2269), maintained in the Laboratório de Soroepidemiologia - Instituto de Medicina Tropical- USP, were exposed to five nitroheterocyclic derivatives, with differences at phenyl-ring position 4: $\mathrm{BSF}-\mathrm{C}_{4} \mathrm{H}_{9}$, BSF-H, BSF-NO ${ }_{2}, \mathrm{BSF}_{-} \mathrm{CH}_{3}$ and BSF-Cl, for 48 hours. After analyzing viability (MTT assay), we evaluated cellular-morphology activity of compounds by transmission electron microscopy (TEM) and measurement of apoptosis (phosphatidylserine expression) by flow cytometry. Results: $\mathrm{EC}_{50}$ of amphotericin $\mathrm{B}$ and BSF- $\mathrm{CH}_{3}$ were $0.50 \mu \mathrm{M}$ and $0.39 \mu \mathrm{M}$ respective. Other nitro-heterocyclic compounds presented $\mathrm{EC}_{50}$ higher than amphotericin $\mathrm{B}$. All compounds showed greater AV- and PI-positive expression than amphotericin B at $100 \mu \mathrm{M}$, except $\mathrm{BSF}-\mathrm{NO}_{2}$. TEM showed complete nuclear disfigurement with $100 \mu \mathrm{M}$ of BSF- $\mathrm{NO}_{2}, 25$ and $6.25 \mu \mathrm{M}$ of BSF-H, and $6.25 \mu \mathrm{M} \mathrm{BSF-Cl}$; presence of vesicles within the flagellar pocket with $25 \mu \mathrm{M}$ BSF-H; alteration of the kinetoplast with $25 \mu \mathrm{M}$ BSF- $\mathrm{C}_{4} \mathrm{H}_{9}, 25 \mu \mathrm{M}$ of BSF-H, $6.25 \mu \mathrm{M}$ BSF- $\mathrm{CH}_{3}$ and $6.25 \mu \mathrm{M}$ of BSF-Cl.

Conclusions: Nitro-heterocyclic compounds have shown activity against promastigotes of L. amazonensis, at lower concentrations. However, improvement of compound scaffolds are needed to assist the elucidation of the mechanism of action and to achieve greater activity.
\end{abstract}

\footnotetext{
* Correspondence: 


\section{Background}

About 1 billion people are affected by one or more neglected diseases. These diseases are associated with malnutrition, poverty, population displacement, poor housing and lack of resources [1]. Leishmaniasis is a neglected tropical disease, endemic in 98 countries, with approximately one million individuals affected. Brazil reports approximately 26,000 new cases per year [2]. It may include visceral, cutaneous or mucosal clinical manifestations, directly associated with Leishmania species, which causes the infection [3]; [4]; [5]. American cutaneous leishmaniasis (ACL) is characterized by different types of tegumentary manifestations, and is caused by several Leishmania species. However, Leishmania (L.) amazonesis is one of main species causing tegumentary leishmaniasis in Brazil, and can produce diffuse cutaneous, mucocutaneous and cutaneous manifestations, which are the most common presentation of ACL [4]. Only three drugs, namely pentavalent antimonials, amphotericin B and pentamidine [6]; [7]; [8], are currently used in the treatment of leishmaniasis, even before miltefosine. In view of the long period of treatment, painful injections, appearance of resistance, high costs and side effects that include nephrotoxicity, myalgia, pancreatitis, and others [9], these treatment options are limited. Advances in drug research produce an imperfect framework, which is not democratic since they do not benefit all individuals requiring treatment [10]. In 29 years, only 1,556 new drugs have been released on the market for the treatment of tropical diseases, with the last one having been developed in 2004 [11]. The search for new compounds for leishmaniasis treatment is necessary and urgent, due to the high toxicity of the drugs currently employed to treat it. Nitro-heterocyclic compounds have shown a significant activity against Trypanosoma cruzi [12], [13], which, like Leishmania, is a genus from the family Trypanosomatidae. Furthermore, a previous publication from our group reported activity by nitro-heterocyclic compounds against Leishmania (L.) infantum [14]. Herein, the studied compounds were designed, by molecular modification, based on the nifuroxazide denominated 5-nitro-2-furfurylidene-4hydroxy-benzohydrazide, an antimicrobial agent. Because of its oxidative stress-inducing ability [13], studies have shown that the nitro group at position 5 of the furan ring is essential for the performance of antiparasitic activity. Therefore, this study aimed to evaluate, in vitro, the effect of nitro-heterocyclic compounds on promastigote forms of Leishmania (L.) amazonensis by flow cytometry analysis to detect phosphatidylserine expression and also by transmission electron microscope (TEM) to analyze the ultrastructural modifications of promastigotes.

\section{Methods}

\section{Animals}

$\mathrm{BALB} / \mathrm{c}$ mice, heterogenic, male, aged 40 to 60 days, were obtained from "Biotério da Faculdade de Medicina" (Animal Facility) - Universidade de São Paulo (São Paulo University), were housed under controlled temperature and $12 \mathrm{~h} / 12 \mathrm{~h}$ light cycle with food for Laboratory rodents (NUVITAL, BRAZIL) and water ad libitum. All procedures involving experimental animals were approved by the Ethics Committee (CEUA 0440/9) and following the guidelines of the Brazilian College for Experiments with Animal (COBEA-law 11.794/2008).

\section{Parasite culture}

The infected mice by L. (L.) amazonensis promastigotes (MHO/ $\mathrm{BR} / 73 / \mathrm{M} 2269)$ were euthanized through via intraperitoneal (I,p.) administration of xylazine/ketamine anesthetizing cocktail. After this, the paw was macerated and centrifuged at $1550 \mathrm{~g}$ for $10 \mathrm{~min}$. The pellet obtained was resuspended in $199 \mathrm{Hanks}$ culture medium (CULTILAB, BRAZIL), pH 7.0, enriched with $10 \%$ Fetal Bovine Serum (CRIPION), gentamicin and penicillin, maintained in a BOD greenhouse (Biochemical Oxygen Demand) at $26^{\circ} \mathrm{C}$, and used in the experiment.

\section{Nitro-heterocyclic compounds}

The five compounds, 4-R-substituted-N'-[(5-nitrofuran2-yl)methylene]benzohydrazide $\left(\mathrm{R}=-\mathrm{H},-\mathrm{Cl},-\mathrm{NO}_{2},-\mathrm{CH}_{3}\right.$, $-\mathrm{C}_{4} \mathrm{H}_{9}$ ), were obtained through the molecular modification of nifuroxazide, 4-Hydroxy-N'-[(5-nitrofuran-2-yl)methylene] benzohydrazide. These compounds, which were previously published by Tavares et al. [12]; [15]; [16], were synthesized and purified and their chemical structures elucidated by nuclear magnetic resonance of ${ }^{1} \mathrm{H}$ and ${ }^{13} \mathrm{C}$ and elemental analysis of $\mathrm{H}, \mathrm{N}$ and $\mathrm{C}$.

Viability assay - MTT [3-(4,5-dimetiltiazol-2yl)-2,5-difenil tetrazolium bromide]: Five million $\left(5 \times 10^{6}\right)$ promastigotes in stationary phase, diluted in RPMI medium without red phenol, were distributed in 96-well plates in triplicate. Compounds were dissolved in dimethyl sulfoxide PA (DMSO) and diluted in RPMI medium, without phenol, to obtain concentrations from $800 \mu \mathrm{M}$ to $0.09 \mu \mathrm{M}$. The final concentration of DMSO in the medium used for dissolving the compounds did not affect parasite viability during the assay. As a negative control, high percentages of DMSO were used in the medium. As a drug control, promastigotes were incubated with amphotericin B at the same concentrations of the compounds. After 48 hours at $32^{\circ} \mathrm{C}, 20 \mu \mathrm{L}$ of MTT (Sigma; $5 \mathrm{mg} / \mathrm{mL}$ in PBS) was added to the parasite culture with or without the compounds and incubated at $26^{\circ} \mathrm{C}$ for 4 hours. Subsequently, $50 \mu \mathrm{L}$ of SDS $10 \%$ was added and incubated overnight at $26^{\circ} \mathrm{C}$. The viability of promastigotes was determined in a microplate reader (Multiskan MCC / 340 - Brazil) at $570 \mathrm{~nm}$ wavelength. The $\mathrm{EC}_{50}$ levels of compounds and amphotericin $\mathrm{B}$ were calculated in comparison to positive control.

\section{Assay of Flow Cytometry (FC) for detection of Phosphatidylserine expression}

To analyze the effect of compounds by flow cytometry (FC), concentrations of $100 \mu \mathrm{M}, 25 \mu \mathrm{M}$ and $6.25 \mu \mathrm{M}$ were used. These concentrations were selected based on better results 


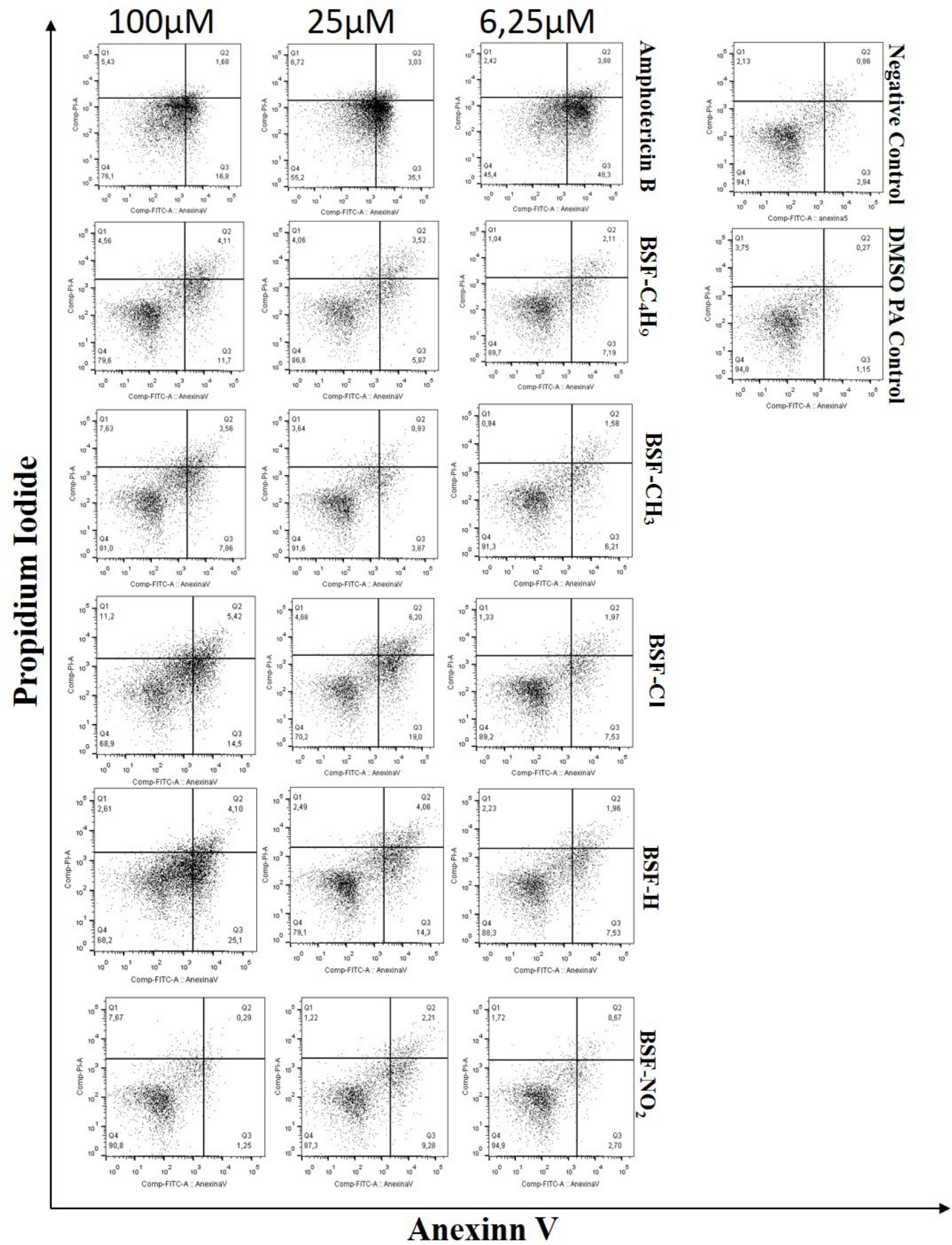

Figure 1 Promastigotes apoptosis determined by Annexin V-FITC staining after treatment with nitro-heterocyclic derivatives and amphotericin B. Flow cytometer analysis of the apoptotic and necrotic cells after incubation of 48 hours in presence of the substituted compounds. Negative Control (untreated) and DMSO PA control. Data are represented in dot-plot. Annexin V -FITC (X axis) and Propidium lodide (PI) - PE (Y axis). 
obtained by Petri e Silva et al., 2016 [14]. Phosphatidylserine externalization was detected by Annexin V - FITC method (BD, USA) according to the manufacturer's instructions. Briefly, $10^{6}$ L. amazonensis promastigotes were incubated with nitroheterocyclic compounds at three concentrations (100, 25 and $6.25 \mu \mathrm{M}$ ) for 48 hours at $32^{\circ} \mathrm{C}$ and $5 \%$ of $\mathrm{CO}_{2}$. Parasites were washed with sterile $\mathrm{PBS}$, and immediately resuspended in binding buffer (BB) [1X]. Five microliters of fluorochromeconjugated Annexin V was added to each $100 \mu \mathrm{L}$ of the cell suspension and incubated for $15 \mathrm{~min}$ at room temperature, protected from light. Next, cells were washed again and resuspended in $200 \mu \mathrm{L}$ of BB. Five microliters of propidium iodide (PI) staining solution (Becton-Dickinson, USA) was added, and the samples were analyzed in a Fortessa SRL Flow Cytometer (Becton-Dickinson, USA). The positive control of phosphatidylserine detection was induced by camptothecin. Cells were gated on forward and side scatter signals to eliminate debris from analysis. All fluorescence parameters were recorded with logarithmic amplification. Analysis was performed on 10,000 gated events stored on FACS DIVA; data were analyzed using the software program FlowJo (Treestar, USA). Three independent experiments were conducted, and the results were analyzed as follows: Annexin V negative - PI negative, indicates the intact membrane plasmatic or live cells; 2) Annexin V positive - PI negative, indicates the cells initiated apoptosis and 3) Annexin V positive - PI positive, represents late apoptotic or necrotic cells.

\section{Transmission Electron Microscopy (TEM): Analysis of the ultrastructural modifications of the promastigotes}

TEM was employed to analyze the effect of compounds at the following concentrations: $100 \mu \mathrm{M}, 25 \mu \mathrm{M}$ and $6.25 \mu \mathrm{M}$. These concentrations were selected based on better results obtained by Petri e Silva et al., 2016 [14]. Promastigotes were seeded in 199 Hanks medium with each of the nitro-heterocyclic compounds $(100 \mu \mathrm{M}, 25 \mu \mathrm{M}$ and $6.25 \mu \mathrm{M}$.) and amphotericin B for $48 \mathrm{~h}$, at $32^{\circ} \mathrm{C}$ in $5 \% \mathrm{CO}_{2}$. After this, promastigotes were fixed overnight at $4{ }^{\circ} \mathrm{C}$, with $2.5 \%$ glutaraldehyde, in $0.1 \mathrm{M}$ cacodylate buffer, $\mathrm{pH}$ 7.2. Cells were washed in cacodylate buffer and postfixed with $1 \% \mathrm{OsO}_{4}, 0.8 \%$ potassium ferrocyanide and $5 \mathrm{mM} \mathrm{CaCl}_{2}$ in the same buffer for $1 \mathrm{~h}$, at room temperature. Next, they were dehydrated in graded acetone, embedded in Epon (propylene oxide) 1:1 and then washed in the same buffer. Ultra-thin sections were mounted on 300- mesh grids, stained with uranyl acetate and lead citrate. After this, ultrastructural modifications of promastigotes were examined using TEM JEOL JEM 1400.

\section{Statistical Analysis}

Statistical analysis was performed using the sigmoidal doseresponse curves with the software GraphPad Prism, version 5.0 for Windows to find the effective concentration of $50 \%\left(\mathrm{EC}_{50}\right)$.

\section{Results \\ Cytotoxicity analysis}

Viability of L. amazonensis in the presence of nitro-heterocyclic compounds and amphotericin B is presented in Table 1. The respective $\mathrm{EC}_{50}$ of amphotericin $\mathrm{B}$ and $\mathrm{BSF}-\mathrm{CH}_{3}$ were $0.50 \mu \mathrm{M}$ and $0.39 \mu \mathrm{M}$. Other nitroheterocyclic compounds presented $\mathrm{EC}_{50}$ higher than amphotericin $\mathrm{B}$.

\section{Assay of Flow Cytometry (FC) for detection of Phosphatidylserine expression}

Each concentration of amphotericin B, and all nitro-compounds, except BSF- $\mathrm{NO}_{2}$ at $6.25 \mu \mathrm{M}$, presented a higher phosphatidylserine index in relation to the negative control. All compounds showed $\mathrm{AV}$ - and PI-positive expression in relation to amphotericin $\mathrm{B}$ at $100 \mu \mathrm{M}$, except BSF- $\mathrm{NO}_{2}$, which induced late apoptosis (Table 2 and Fig.1). The negative control showed PI fluorescence intensity of $2.94 \%$. BSF- $\mathrm{NO}_{2}$ and $\mathrm{BSF}-\mathrm{CH}_{3}$ compounds showed no significant difference from the negative control.

\section{Transmission Electron Microscopy (TEM): Analysis of the ultrastructural modifications of the promastigotes}

According to Figure 2 (A-B), untreated promastigotes showed elongated and preserved structure. All organelles from promastigotes treated with amphotericin $B$ presented intense and important denaturation (Fig $2 \mathrm{~L}-\mathrm{M}$ ). The following conditions of promastigotes were observed according to concentrations of compounds: 1- mitochondrial swelling around the kinetoplast, retraction of flagella, presence of innumerous vacuoles in the flagellar pocket, nuclear disorganization and rounding of the parasite, when treated with $25 \mu \mathrm{M}$ and $6.25 \mu \mathrm{M}$ of BSF-H; 2 - DNA decondensation promoted by modification of nuclear morphology with $6.25 \mu \mathrm{M}$ of BSF- $\mathrm{CH}_{3}$; 3-vacuoles in the flagellar pocket, absence of chromatin and nuclear material, mitochondrial fragmentation and intense cytoplasmic alterations, but with elongated structure with $1.56 \mu \mathrm{M}$ of BSF-Cl; 4 - rounding of the parasite, mitochondrial fragmentation, nuclear disorganization and total or partial retraction of flagella, with $25 \mu \mathrm{M} \mathrm{BSF}-\mathrm{C}_{4} \mathrm{H}_{9}$; and 5 - intense presence of vacuoles in the flagellar pocket and cytoplasm, mitochondrial swelling and nuclear alterations with BSF- $\mathrm{NO}_{2}$. By TEM, the promastigotes were analyzed using intermediate concentrations of the compounds. According to the results of FC (Figure 2) and MTT assay (Table 1) we observed the following: complete nuclear disfigurement with $100 \mu \mathrm{M}$ of BSF-NO $_{2}$ (C), 25 and $6.25 \mu \mathrm{M}$ of BSF-H (F-G-H) and $6.25 \mu \mathrm{M}$ BSF-CL (J); presence of vesicles within the flagellar pocket with $25 \mu \mathrm{M}$ BSF-H (F) and alteration of the kinetoplast with $25 \mu \mathrm{M}$ BSF-C $_{4} \mathrm{H}_{9}$ (D-E), $25 \mu \mathrm{M}$ of BSF-H (F), $6.25 \mu \mathrm{M}$ BSF-CH $\mathrm{CH}_{3}$ (I) and $6.25 \mu \mathrm{M}$ of BSF-Cl (K). Detachment of the nuclear membrane, chromatin condensation, loss of organelles in the cytoplasm and total parasite disfigurement were observed in parasites treated with amphotericin B. 
Table 1 Viability determination of $L$. (L.) amazonensis in presence of nitro-heterocyclic compounds and amphotericin B.

\begin{tabular}{lcc}
\hline Compounds & EC $_{\mathbf{5 0}}(\boldsymbol{\mu M})$ & $\mathbf{C l} \mathbf{9 5 \%}$ \\
\hline Amphotericin $\mathrm{M}$ & 0.50 & $0.6-0.3$ \\
$\mathrm{BSF}_{-} \mathrm{C}_{4} \mathrm{H}_{9}$ & 0.82 & $1.2-0.5$ \\
$\mathrm{BSF}-\mathrm{CH}_{3}$ & 0.39 & $0.5-0.2$ \\
$\mathrm{BSF}-\mathrm{Cl}$ & 1.2 & $1.4-0.98$ \\
$\mathrm{BSF}-\mathrm{H}$ & 1.2 & $1.45-1.13$ \\
$\mathrm{BSF}^{-\mathrm{NO}_{2}}$ & 0.84 & $0.99-0.70$ \\
\hline
\end{tabular}

EC50:50\% of effective concentration, determined after 48 h of incubation; Cl $95 \%$ : confidence interval of $95 \%$.

Table 2 Detection of phosphatidylserine expression by Annexin $\vee$ method on $L$.(L) amazonensis promatigotes exposed to different concentrations of nitroheterocyclic derivatives and amphotericin B.

\begin{tabular}{|c|c|c|c|}
\hline & PI+ (\%) & $A V+(\%)$ & PI+ AV+ (\%) \\
\hline Negative Control & 2.13 & 2.94 & 0.86 \\
\hline DMSO PA Control & 3.75 & 1.15 & 0.27 \\
\hline \multicolumn{4}{|l|}{$[100 \mu \mathrm{M}]$} \\
\hline Amphotericin B & 5.43 & 16.8 & 1.68 \\
\hline BSF- $\mathrm{C}_{4} \mathrm{H}_{9}$ & 4.56 & 11.7 & 4.11 \\
\hline BSF-CH $\mathrm{CH}_{3}$ & 7.63 & 7.86 & 3.56 \\
\hline BSF-Cl & 11.2 & 14.5 & 5.42 \\
\hline BSF-H & 2.61 & 25.1 & 4.1 \\
\hline BSF-NO & 7.67 & 1.25 & 0.29 \\
\hline \multicolumn{4}{|l|}{$[25 \mu \mathrm{M}]$} \\
\hline Amphotericin B & 6.72 & 35.1 & 3.03 \\
\hline BSF- $\mathrm{C}_{4} \mathrm{H}_{9}$ & 4.06 & 5.87 & 3.52 \\
\hline BSF-CH $\mathrm{CH}_{3}$ & 3.64 & 3.87 & 0.93 \\
\hline BSF-Cl & 4.68 & 19 & 6.2 \\
\hline BSF-H & 2.49 & 14.3 & 4.06 \\
\hline \multicolumn{3}{|l|}{$[6.25 / \mathrm{M}]$} & 2.21 \\
\hline Amphotericin B & 2.42 & 48.3 & 3.88 \\
\hline BSF- $\mathrm{C}_{4} \mathrm{H}_{9}$ & 1.04 & 7.19 & 2.11 \\
\hline BSF-CH $\mathrm{CH}_{3}$ & 0.94 & 6.21 & 1.58 \\
\hline BSF-Cl & 1.33 & 7.53 & 1.97 \\
\hline BSF-H & 2.23 & 7.53 & 1.96 \\
\hline BSF-NO & 1.72 & 2.7 & 0.67 \\
\hline
\end{tabular}

Data expressed by the percentage of the average fluorescence intensity of Annexin V-FITC and Propidium lodide-PE on L.(L) amazonensis promatigotes. Incubation for 48 hours, at $32{ }^{\circ} \mathrm{C}$ and $5 \%$ of $\mathrm{CO} 2 . \mathrm{AV}+(\mathrm{Q} 3)$ : Annexin $\mathrm{V}$ positive; $\mathrm{Pl}+(\mathrm{Q} 1)$ : Propidium iodide positive PI+ $\mathrm{AV}+(\mathrm{Q} 2)$ : Annexin $\mathrm{V}$ and Propidium iodide positive; Negative control: promastigotes untreated.

\section{Discussion}

Although leishmaniasis is a disease of epidemiological relevance, it remains neglected and lacks an adequate treatment. Thirty to 50 percent of patients treated with the current drugs usually present with side effects such as tachycardia, skin lesions, headaches and vomiting. After continuous treatment, effects such as hypotension, hypoglycemia, cardiac changes, nephrotoxicity and sudden death have been described [4]; [8]. Considering these shortcomings in the treatments currently available for leishmaniasis, the search for new more effective compounds against the disease is fundamental. It should be noted that there are few new drugs on the world market for tropical diseases. It is known that of the 1,223 therapeutic chemicals introduced and marketed worldwide between 1975 and 1996, 379 are actually therapeutic innovations and less than $1 \%$ of these innovations were intended for tropical diseases including 


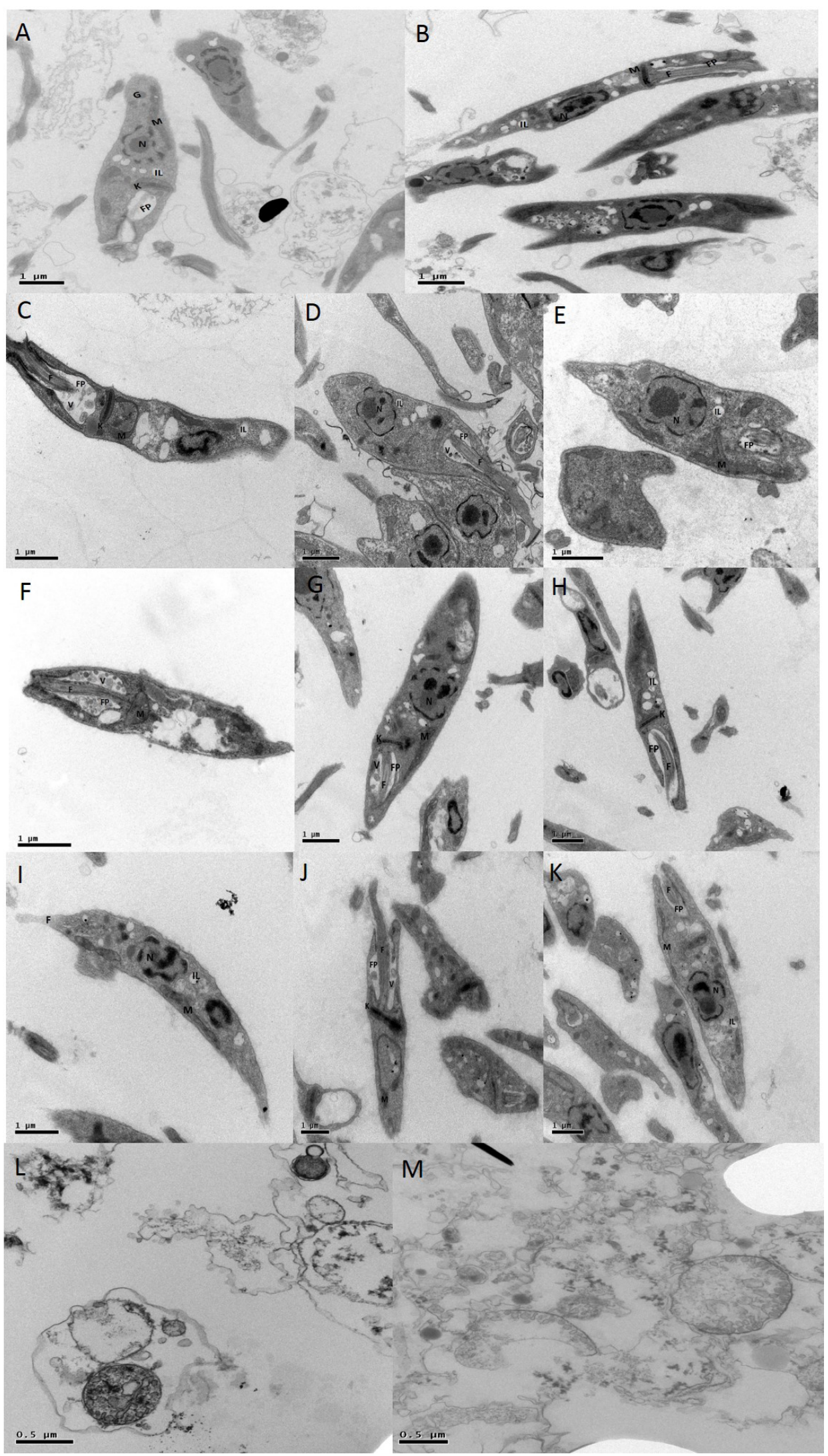

Figure 2 Promastigotes analyzed by TEM (Transmission Electron Microscopy) after exposure to nitro-heterocyclic compounds and controls. A/B - Negative control; C - BSF-NO $100 \mu \mathrm{M}$; D/E- BSF-C $\mathrm{H}_{9} 25 \mu \mathrm{M}$; F - BSF-H $25 \mu \mathrm{M}$; G/H - BSF-H $6.25 \mu \mathrm{M}$; I - BSF-CH $6.25 \mu \mathrm{M}$; J/K - BSF-Cl $1.56 \mu$ M; L - Positive Control Amphotericin B $100 \mu \mathrm{M}$; M - Positive control Amphotericin B $25 \mu \mathrm{M}$. N - Nucleus; FP - Flagellar Pocket; K - Kinetoplast; V - Vesicles; IL - Inclusions Lipid; M Mitochondria; G - Glicossome. 
leishmaniasis [11]; [17]. Additionally, there is an increase of resistance to the drugs presently utilized to treat leishmaniasis. Drug combination is an interesting leishmanicidal chemotherapy and has shown some usefulness, since Leishmania spp has developed different immunomodulatory strategies that are essential for the establishment of the infection. Understanding the mechanisms associated with immune evasion and disease progression becomes essential for the development of novel therapies and vaccine approaches. Furthermore, more knowledge about public health policies to develop leishmanicidal drugs is also required.

Recently, research targeting the molecular and cellular machinery of the parasite, including using in vitro and in vivo studies has been conducted. Enzymes involved in synthesis of polyamines, including trypanothione reductase, are essential for the survival of Leishmania spp, justifying them as drug targets, such as proteases and arginase and transports via LdAAP3 and LdAAP7. A strategy to increase drug distribution through the liposomal intramononuclear phagocyte system has been explored [18]. Nitro-heterocyclic compounds are antimicrobial drugs [19] that have been shown to be a treatment option against trypanosomatids. Since the 1950s Evans Niemegeers and Pakchanian, have identified them as an alternative therapy for Chagas disease and sleeping sickness [20]. The action mechanism of these compounds is unclear; however, it is known to be based on inhibiting the mitochondrial respiration, lipid peroxidation, inactivation of peroxidases and glycolysis arginases [19].

In the current study L. amazonensis promastigotes were exposed to nitroheterocyclic compounds at different concentrations for 48 hours. Apoptosis was observed in $71.2 \%$ of the parasites exposed to the compound BSF-H and only in $62.3 \%$ of those exposed to amphotericin $\mathrm{B}$, showing that the BSF-H can be as effective as amphotericin B. The MTT assay (viability) revealed that, when tested at low concentrations, the compounds proved to be good candidates for in vivo studies, presenting an $\mathrm{EC}_{50}$ up to $0.39 \mu \mathrm{M}\left(\mathrm{BSF}-\mathrm{CH}_{3}\right)$, more effective than the positive control, amphotericin $\mathrm{B}$. Therefore, the compound was capable of inhibiting the growth of Leishmania at lower concentrations. Evaluation of phosphatidylserine externalization [21] was used for cellular apoptosis analysis. Phosphatidylserine is a phospholipid located in the interior of plasma membrane that shifts to the surface of the cellular membrane, through breakage of this membrane in apoptotic cells. Annexin V is a binding protein dependent on phospholipid calcium that binds preferentially to phosphatidylserine [22]. In the current study Annexin $\mathrm{V}$ was employed to evaluate the externalization of phosphatidylserine. Changes in cell membrane integrity were analyzed by PI staining, characterized by intercalating the DNA of parasites with a compromised membrane, alterations not presented by live parasites with an intact membrane [21]; [22] [23]. In the present study, all compounds showed greater AV-and PI-positive expression in relation to amphotericin B at $100 \mu \mathrm{M}$, except BSF-NO $\mathrm{N}_{2}$. The parasites treated with higher concentrations of BSF-Cl and BSF-H presented apoptosis when analyzed by flow cytometry, which did not occur when they were treated with the higher concentrations of BSF- $\mathrm{C}_{4} \mathrm{H}_{9}, \mathrm{BSF}-\mathrm{NO}_{2}$ and $\mathrm{BSF}-\mathrm{CH}_{3}$. With these compounds, parasites entered apoptosis at lower concentrations. Transmission electron microscopy (TEM), an excellent assay for the evaluation of morphological changes of the parasites [24], was utilized to compare the morphology of viable parasites (negative control) versus those treated with the nitrocompounds. Usually promastigotes present elongated fusiform morphology with a nucleus and highly defined kinetoplast. However, the parasites treated with these compounds presented morphological changes such as formation of vesicles inside the flagellar pocket, disfigurement of the nucleus and shrinkage of parasites. Such characteristics have already been described by Rodrigues et al., 2008 [25]; Medeiros et al., 2011 [26] and Rottini et al., 2015 [27] in studies of compounds with possible antileishmania activity. In this study, TEM showed complete nuclear disfigurement after administration of $100 \mu \mathrm{M}$ of BSF$\mathrm{NO}_{2}, 25$ and $6.25 \mu \mathrm{M}$ of BSF-H and $6.25 \mu \mathrm{M}$ BSF-Cl; presence of vesicles within the flagellar pocket at $25 \mu \mathrm{M}$ BSF-H; alteration of the kinetoplast after $25 \mu \mathrm{M}$ BSF- $\mathrm{C}_{4} \mathrm{H}_{9}, 25 \mu \mathrm{M}$ of BSF- $\mathrm{H}, 6.25$ $\mu \mathrm{M} \mathrm{BSF}-\mathrm{CH}_{3}$ and $6.25 \mu \mathrm{M}$ of BSF-Cl.

The nitro-heterocyclic compounds have shown effective in vitro activity, by inhibiting the growth of T. cruzi epimastigotes and amastigotes [12]. This result suggested that a similar activity could be found against Leishmania, since both parasites belong to the family Trypanosomatidae, as found against Leishmania (L.) infantum [14]. Nevertheless, despite the similarity between these protozoa, it is believed that the molecular modification at position 4 of the phenyl ring of the compounds can result in significant changes of molecular properties and trigger distinct responses in each protozoan. These observations suggested that further analysis including more substitutions in nitrocompounds may help elucidate activity against Leishmania in comparison to T. cruzi.

\section{Conclusions}

All compounds analyzed show in vitro activity against Leishmania (L.) amazonensis promastigotes, especially those compounds at lower concentrations. Further investigations are required to determine the mechanism of the nitro-heterocyclic action in Leishmania.

\section{Abbreviations}

Not applicable.

\section{Availability of data and materials}

All data generated or analyzed during this study are included in this published article.

\section{Funding}

Coordenação de Aperfeiçoamento de Pessoal de Nível Superior, CAPES (LCT and FPB); Fundação de Amparo à Pesquisa do 
Estado de São Paulo, FAPESP (grant number 2014/06061-4 - LCT and FPB). LIM 38 (HC-FMUSP) for financial support. Moreover, This publication was supported in part by the Coordination for the Improvement of Higher Education Personnel (CAPES) through "Programa Editoração CAPES" - call No. 3/2016, grant No. 0722/2017, record No. 88881.142062/2017-01 and by the National Council for Scientific and Technological Development (CNPq) and Coordination for the Improvement of Higher Education Personnel (CAPES) through "Programa Editorial CNPq/CAPES” call No. 18/2018, grant No. 404770/2018-5.

\section{Competing interests}

The authors declare that there are no conflicts of interest.

\section{Authors' contributions}

DBDM designed and performed all experiments and wrote the manuscript. RECS take part in the experiments related to cytometry. FPB was responsible for synthesis of compounds and corrected the manuscript. CFHT took part in the experiments related to transmission electron microscopy. SRCS helped in all experiments. LMAB helped to write the manuscript. LCT was responsible for compounds and corrected the manuscript. JALL designed the experiments, and wrote and corrected the manuscript.

\section{Ethics approval and consent to participate}

All procedures involving experimental animals were approved by the Ethics Committee (CEUA 0440/9) and following the guidelines of the Brazilian College for Experiments with Animal (COBEA-law 11.794/2008). Consent to participate is not applicable.

\section{Consent for publication}

Not applicable.

\section{References}

1. World Health Organization. Leishmaniasis. Magnitude of the problem. WHO. 2015.

2. Alvar J, Vélez ID, Bern C, Herrero M, Desjeux P, Cano J, et al. Leishmaniasis worldwide and global estimates of its incidence. PLoS One. 2012;7(5):e35671.

3. Silveira FT, Lainson R, Corbett CEP. Clinical and immunopathological spectrum of american cutaneous leishmaniasis with special reference to the disease in Amazonian Brazil - a review. Mem Inst Oswaldo Cruz. 2004;99(3):239-51.

4. Goto H, Lindoso JA. Current diagnosis and treatment of cutaneous and mucocutaneous leishmaniasis. Expert Rev Anti Infect Ther. 2010;8(4):419-33.

5. Handler MZ, Patel PA, Kapila R, Al-Qubati Y, Schwartz RA. Cutaneous and mucocutaneous leishmaniasis. J Am Acad Dermatol. 2015;73(6):897908.

6. Tasdemir D, Kaiser M, Brun R, Yardley V, Schmidt TJ, Tosun F, et al. Antitrypanosomal and antileishmanial activities of flavonoids and their analogues: in vitro, in vivo, structure-activity relationship, and quantitative structure-activity relationship studies. Antimicrob Agents Chemother. 2006;50(4):1352-64.
7. da Cunha-Júnior EF, Pacienza-Lima W, Ribeiro GA, Netto CD, do Canto-Cavalheiro MM, da Silva AJ, et al. Effectiveness of the local or oral delivery of the novel naphthopterocarpanquinone LQB-118 against cutaneous leishmaniasis. J Antimicrob Chemother. 2011;66(7):1555-9.

8. Copeland NK, Aronson NE. Leishmaniasis: treatment updates and clinical practice guidelines review. Curr Opin Infect Dis. 2015;28(5):426-37.

9. Ribeiro TG, Chávez-Fumagalli MA, Valadares DG, França JR, Rodrigues LB, Duarte MC, et al. Novel targeting using nanoparticles: an approach to the development of an effective anti-leishmanial drug-delivery system. Int J Nanomedicine. 2014;9:877-90.

10. Chappuis F, Alirol E, Worku DT, Mueller Y, Ritmeijer K. High mortality among older patients treated with pentavalent antimonials for visceral leishmaniasis in East Africa and rationale for switch to liposomal amphotericin B. Antimicrob Agents Chemother. 2011;55(1):455-6.

11. Annual Report - DNDi - Drugs for Neglect Diseases Initiative. 2016.

12. Palace-Berl F, Jorge SD, Pasqualoto KF, Ferreira AK, Maria DA, Zorzi $\mathrm{RR}$, et al. 5-Nitro-2-furfurilien derivates as potential anti-Trypanossoma cruzi agents: design, synthesis, bioactivity evaluation, cytotoxicity and exploratory data analysis. Bioorg Med Chem. 2013;21(17):5395-406.

13. Palace-Berl F, Pasqualoto KFM, Zingales B, Moraes CB, Bury M, Franco $\mathrm{CH}$, et al. Investigating the structure-activity relationships of $\mathrm{N}^{\prime}$-[(5nitrofuran-2-yl) methylene] substituted hydrazides against Trypanosoma cruzi to design novel active compounds. Eur J Med Chem. 2018;144: 29-40.

14. Petri e Silva SC, Palace-Berl F, Tavares LC, Soares SRC, Lindoso JAL. Effects of nitro-heterocyclic derivatives against Leishmania (Leishmania) infantum promastigotes and intracellular amastigotes. Exp Parasitol. 2016;163:68-75.

15. Tavares LC, Penna TC, Amaral AT. Synthesis and biological activity of nifuroxazide and analogs. Boll Chim Farm. 1997;136(3):244-9.

16. Paula FR, Jorge SD, de Almeida LV, Pasqualoto KFM, Tavares LC. Molecular modeling studies and in vitro bioactivity evaluation of a set of novel 5-nitro-heterocyclic derivatives as anti-T. cruzi agents. Bioorg Med Chem. 2009;17(7):2673-9.

17. Trouiller P, Olliaro PL. Drug development output from 1975 to 1996: what proportion for tropical diseases? Int J Infect Dis. 1999;3(2):61-3.

18. Prati F, Goldman-Pinkovich A, Lizzi F, Belluti F, Koren R, Zilberstein D, et al. Quinone-amino acid conjugates targeting Leishmania amino acid transporters. PLoS One. 2014;9(9):e107994.

19. Zorzi RR, Jorge SD, Palace-Berl F, Pasqualoto KF, Bortolozzo LS, de Castro Siqueira AM, et al. Exploring 5-nitrofuran derivatives against nosocomial pathogens: synthesis, antimicrobial activity and chemometric analysis. Bioorg Med Chem. 2014;22(10):2844-54.

20. Evens F, Niemegeers K, Packchanian A. Chemotherapy of Trypanosoma gambiense and Trypanosoma rhodesiense infections in guinea pigs with nitrofurazone. Am J Trop Med Hyg. 1957;6(4):658-64.

21. Fonseca-Silva F, Canto-Cavalheiro MM, Menna-Barreto RF, AlmeidaAmaral EE. Effect of Apigenin on Leishmania amazonensis is associated with reactive oxygen species production followed by mitochondrial dysfunction. J Nat Prod. 2015;78(4):880-4.

22. Machado M, Dinis AM, Santos-Rosa M, Alves V, Salgueiro L, Cavaleiro C, et al. Activity of Thymus capitellatus volatile extract, 1,8-cineole and borneol against Leishmania species. Vet Parasitol. 2014;200(1-2):39-49.

23. Kulkarni MM, McMaster WR, Kamysz W, McGwire BS. Antimicrobial peptide-induced apoptotic death of Leishmania results from calciumdependent, caspase-independent mitochondrial toxicity. J Biol Chem. 2009;284(23):15496-504.

24. Britta EA, Scariot DB, Falzirolli $H$, Ueda-Nakamura T, Silva CC, Filho BP, et al. Cell death and ultrastructural alterations in Leishmania amazonensis caused by new compound 4-Nitrobenzaldehyde thiosemicarbazone derived from S-limonene. BMC Microbiol. 2014;14:236.

25. Fernandes Rodrigues JC, Concepcion JL, Rodrigues C, Caldera A, Urbina JA, de Souza W. In vitro activities of ER-119884 and E5700, two potent squalene synthase inhibitors, against Leishmania amazonensis: antiproliferative, biochemical, and ultrastructural effects. Antimicrob Agents Chemother. 2008;52(11):4098-114. 
26. de Medeiros Md, da Silva AC, Citó AM, Borges AR, de Lima SG, Lopes $\mathrm{JA}$, et al. In vitro antileishmanial activity and cytotoxicity of essential oil from Lippia sidoides Cham. Parasitol Int. 2011;60(3):237-41.
27

Rottini MM, Amaral AC, Ferreira JL, Silva JR, Taniwaki NN, Souza CS, et al. In vitro evaluation of (-)a-bisabolol as a promising agent against Leishmania amazonensis. Exp Parasitol. 2015;148:66-72. 